Check for updates

Cite this: Chem. Sci., 2019, 10, 1150

๑ All publication charges for this article have been paid for by the Royal Society of Chemistry

Received 6th September 2018 Accepted 12th November 2018

DOI: $10.1039 / \mathrm{c} 8 \mathrm{sc} 03969 \mathrm{k}$

rsc.li/chemical-science

\section{Development and mechanistic investigation of the manganese(III) salen-catalyzed dehydrogenation of alcohols $\dagger$}

\author{
Simone V. Samuelsen, ${ }^{a}$ Carola Santilli, ${ }^{a}$ Mårten S. G. Ahlquist ${ }^{\mathrm{b}}$ and Robert Madsen (DD *a
}

The first example of a manganese(III) catalyst for the acceptorless dehydrogenation of alcohols is presented. $N, N^{\prime}$-Bis(salicylidene)-1,2-cyclohexanediaminomanganese(III) chloride (2) has been shown to catalyze the direct synthesis of imines from a variety of alcohols and amines with the liberation of hydrogen gas. The mechanism has been investigated experimentally with labelled substrates and theoretically with DFT calculations. The results indicate a metal-ligand bifunctional pathway in which both imine groups in the salen ligand are first reduced to form a manganese(III) amido complex as the catalytically active species. Dehydrogenation of the alcohol then takes place by a stepwise outer-sphere hydrogen transfer generating a manganese(III) salan hydride from which hydrogen gas is released.

\section{Introduction}

Metal-catalyzed dehydrogenation of alcohols gives rise to aldehydes and ketones, which can be further transformed into imines, amides, esters, carboxylic acids and various heterocycles in the same pot. ${ }^{1}$ The acceptorless dehydrogenation constitutes an attractive synthetic protocol since it does not require any stoichiometric oxidants and only releases hydrogen gas as a co-product. The dehydrogenative transformations are usually catalyzed by complexes of the platinum-group metals such as ruthenium and iridium. ${ }^{1}$ Recently, however, non-noble metal complexes based on iron, cobalt and manganese have also been shown to catalyze alcohol dehydrogenations. ${ }^{2}$ Especially manganese-catalyzed dehydrogenations have been a hot research area since the first catalyst was introduced in $2016 .^{3}$ Since then several research groups have presented different manganese complexes for preparing various functional groups and heterocyclic frameworks (Fig. 1). ${ }^{4}$ These complexes have also been used to catalyze the hydrogenation of carbonyl compounds. ${ }^{5}$ The significance of the discoveries is exemplified by the large number of works published on this topic over the past two years ${ }^{3-6}$ including several reviews. ${ }^{2 a-d}$

Notably, the developed complexes are all manganese(I) compounds with $\mathrm{CO}$ ligands and a pincer ligand. The electron-

${ }^{a}$ Department of Chemistry, Technical University of Denmark, $2800 \mathrm{Kgs}$. Lyngby, Denmark.E-mail: rm@kemi.dtu.dk

${ }^{b}$ Department of Theoretical Chemistry \& Biology, School of Engineering Sciences in Chemistry Biotechnology and Health, KTH Royal Institute of Technology, 10691 Stockholm, Sweden

$\dagger$ Electronic supplementary information (ESI) available: Experimental procedures, kinetic and compound characterization data, copies of ${ }^{1} \mathrm{H}$ and ${ }^{13} \mathrm{C}$ NMR spectra as well as coordinates and energies from DFT calculations. See DOI: $10.1039 / \mathrm{c} 8 \mathrm{sc} 03969 \mathrm{k}$ withdrawing CO ligand is necessary for stabilizing the low oxidation state of manganese. The mechanism for the dehydrogenation with these complexes is believed to involve a catalytic cycle with different manganese(I) species $^{3,4 b, e, 5 b}$ and no catalytic activity is observed without the CO ligands or with the corresponding manganese(II) dihalide complexes. ${ }^{5 d}$ Although manganese is an Earth-abundant and cheap metal, manganese(I) complexes are not inexpensive since they are prepared in several steps from $\mathrm{Mn}_{2}(\mathrm{CO})_{10}$. This carbonyl complex is quite expensive due to its difficult preparation by a carbonylation reaction. ${ }^{7}$ As a result, there is a need for identifying a new and more abundantly available class of manganese complexes for alcohol dehydrogenations. Especially, it would be attractive to catalyze the dehydrogenations by higher valent complexes where stabilization by CO ligands is not necessary.

This prompted the question whether manganese(III) complexes would be able to catalyze the same acceptorless alcohol dehydrogenations? Manganese(III) complexes such as
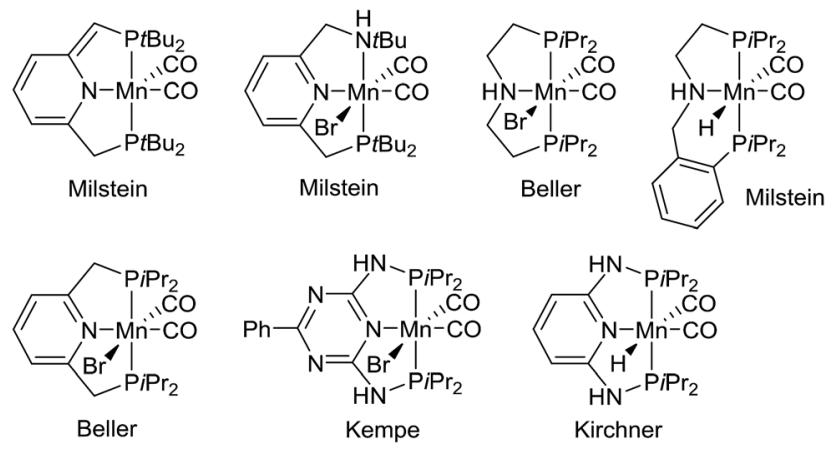

Fig. 1 Manganese(I) complexes for alcohol dehydrogenation., 
the Jacobsen's catalyst ${ }^{8}$ are widely known for catalyzing oxidation reactions in the presence of a stoichiometric oxidant. This includes epoxidation of olefins, oxidation of alcohols as well as hydroxylation and halogenation of alkanes. ${ }^{9}$ The reactions proceed through catalytic cycles with different manganese(III), (Iv) and (v) species. ${ }^{9}$

Herein, we describe the first example of an acceptorless alcohol dehydrogenation catalyzed by a manganese(III) complex. An easily available manganese(III) salen catalyst has been shown to liberate hydrogen gas from alcohols and the transformation has been applied to the synthesis of imines from alcohols and amines. ${ }^{10}$ The mechanism has been investigated by experimental and theoretical methods which indicates a metal-ligand bifunctional pathway ${ }^{\mathbf{1 1}}$ for the removal of hydrogen gas from the alcohol.

\section{Results and discussion}

The transformation was discovered while attempting to develop a more convenient in situ-formed catalyst system (Table 1). Benzyl alcohol was treated with an equimolar amount of cyclohexylamine in the presence of $\mathrm{Mn}_{2}(\mathrm{CO})_{10}$ and different ligands. The most promising result was obtained with $N, N^{\prime}$ bis(salicylidene)ethylenediamine $\left(\mathrm{H}_{2} \mathrm{salen}\right)$ as the ligand (entry 1). Since this is a common ligand for manganese(III) complexes, an experiment was also performed with the Jacobsen's catalyst (1, Fig. 2). Interestingly, this increased the yield to $79 \%$ with some unreacted benzyl alcohol remaining (entry 2). ${ }^{12}$ This observation shows that the acceptorless dehydrogenation of alcohols can also be catalyzed by manganese(III) complexes and a number of experiments were now performed to optimize the

Table 1 Dehydrogenation with manganese salen/salan complexes ${ }^{a}$

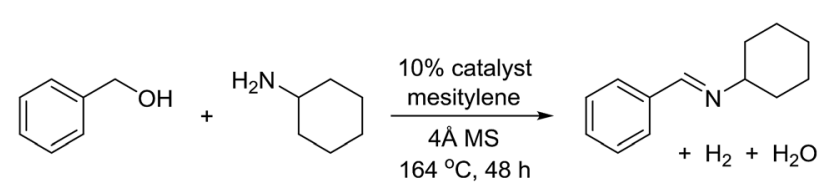

\begin{tabular}{llll}
\hline Entry & Catalyst & BnOH conversion $^{b}(\%)$ & Imine yield $^{c}(\%)$ \\
\hline 1 & $5 \% \mathrm{Mn}_{2}(\mathrm{CO})_{10}$, & - & 38 \\
& $10 \% \mathrm{H}_{2}$ Salen & & \\
2 & $\mathbf{1}$ & 81 & 79 \\
3 & 2 & 86 & 81 \\
4 & 3 & 70 & 65 \\
5 & $\mathbf{4}$ & 66 & 64 \\
6 & $\mathbf{5}$ & 83 & $74^{d}$ \\
7 & 6 & 60 & 58 \\
8 & 7 & 27 & 25 \\
9 & $\mathbf{8}$ & 47 & $12^{e}$
\end{tabular}

${ }^{a}$ Conditions: $\mathrm{BnOH}(1 \mathrm{mmol}), \mathrm{CyNH}_{2}(1 \mathrm{mmol})$, catalyst $(0.1 \mathrm{mmol})$, tetradecane (0.5 mmol, internal standard), $4 \AA$ MS (150 mg), mesitylene $(4 \mathrm{~mL})$, reflux, 48 h. ${ }^{b}$ Determined by GC using the internal standard. ${ }^{c} \mathrm{GC}$ yield based on the internal standard. ${ }^{d} 6 \%$ of $N$ cyclohexylbenzamide was also formed. ${ }^{e}$ Traces of benzyl benzoate was also detected.
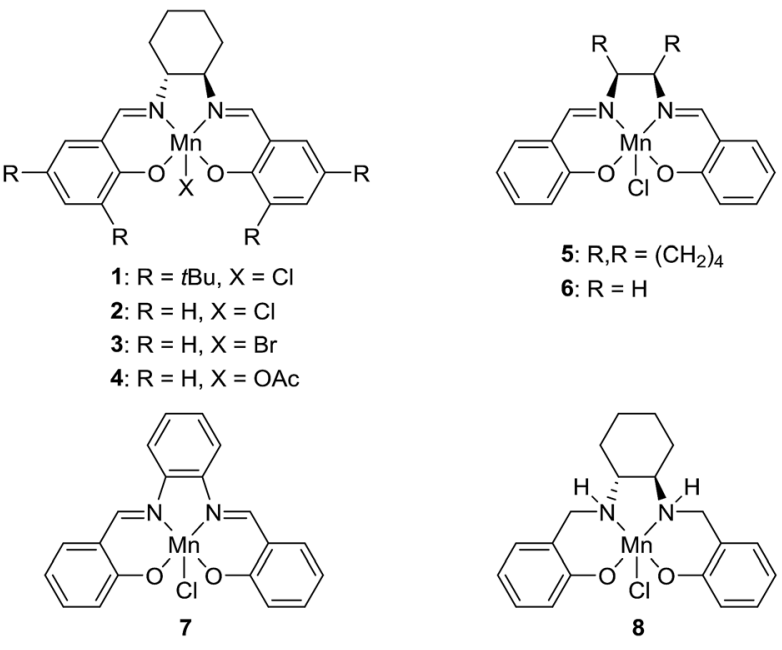

Fig. 2 Manganese(III) salen/salan complexes used in the investigation.

reaction. First, several derivatives of Jacobsen's catalyst were prepared to investigate the influence of the aryl substituent, the axial group on manganese, the scaffold and the Schiff base functionality (Fig. 2). Essentially the same result was obtained with the unsubstituted analogue 2 (entry 3) and the tert-butyl group can therefore be omitted. The axial substituent on manganese, on the other hand, needs to be chloride since both the bromide 3 and the acetate 4 gave significantly lower conversion and yield (entries 4 and 5). The same was observed when the trans-1,2-diaminocyclohexane scaffold was changed to either the cis (i.e. 5), the ethylene (i.e. 6) or the benzene (i.e. 7) analogue (entries 6-8). Notably, the corresponding salan complex 8 also furnished some conversion into the imine (entry 9) which may indicate that the Schiff base functionality in the salen ligand plays an important role in the mechanism (vide infra). In the end, trans- $N, N^{\prime}$-bis(salicylidene)-1,2cyclohexanediamine was selected as the salen ligand for the transformation and thus complex 2 as the catalyst.

For further optimization, the influence of additives and the solvent were investigated (Table 2). A number of common additives ${ }^{13}$ were included in the reaction, but they all led to lower imine yields due to a moderate conversion of benzyl alcohol (results not shown). We have previously used nitride salts as a basic additive for alcohol dehydrogenations, ${ }^{\mathbf{1 4}}$ but lower yields and conversion were also observed when $\mathrm{Li}_{3} \mathrm{~N}$ and $\mathrm{Mg}_{3} \mathrm{~N}_{2}$ were added to the reaction (entries 1 and 2). However, with $\mathrm{Ca}_{3} \mathrm{~N}_{2}$ a complete transformation of benzyl alcohol and a high yield of the imine was now obtained (entry 3). The optimum amount of $\mathrm{Ca}_{3} \mathrm{~N}_{2}$ was $16.7 \%$ since both higher and lower quantities decreased the yield of the imine (entries 4-7). We observed the same optimum percentage in our earlier work $^{\mathbf{1 4}}$ and $\mathbf{1 6 . 7 \%}$ is an intriguing number since one equiv. of $\mathrm{Ca}_{3} \mathrm{~N}_{2}$ can theoretically react as a base with 6 equiv. of either the alcohol or water.

The influence of the solvent was then investigated and a slightly improved outcome was observed upon conducting the reaction in toluene (entry 8). Dioxane and heptane gave lower 
Table 2 Optimization of dehydrogenation with complex $2^{a}$

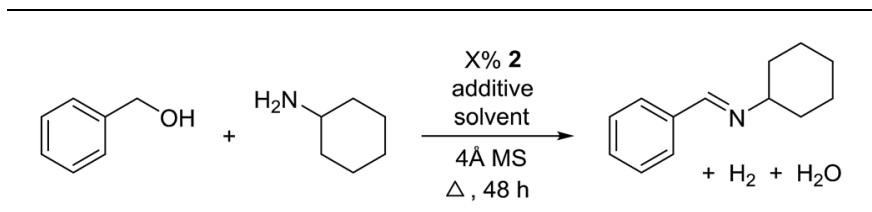

\begin{tabular}{llllll}
\hline Entry & $\mathrm{X}$ & Additive & Solvent & Conversion $^{b}(\%)$ & Yield $^{c}(\%)$ \\
\hline 1 & 10 & $20 \% \mathrm{Li}_{3} \mathrm{~N}$ & Mesitylene & 66 & $12^{d}$ \\
2 & 10 & $20 \% \mathrm{Mg}_{3} \mathrm{~N}_{2}$ & Mesitylene & 54 & 48 \\
3 & 10 & $20 \% \mathrm{Ca}_{3} \mathrm{~N}_{2}$ & Mesitylene & 100 & 92 \\
4 & 10 & $16.7 \% \mathrm{Ca}_{3} \mathrm{~N}_{2}$ & Mesitylene & 100 & 93 \\
5 & 10 & $33 \% \mathrm{Ca}_{3} \mathrm{~N}_{2}$ & Mesitylene & 100 & 84 \\
6 & 10 & $10 \% \mathrm{Ca}_{3} \mathrm{~N}_{2}$ & Mesitylene & 100 & 90 \\
7 & 10 & $5 \% \mathrm{Ca}_{3} \mathrm{~N}_{2}$ & Mesitylene & 100 & 88 \\
8 & 10 & $16.7 \% \mathrm{Ca}_{3} \mathrm{~N}_{2}$ & Toluene & 100 & 98 \\
9 & 10 & $16.7 \% \mathrm{Ca}_{3} \mathrm{~N}_{2}$ & Dioxane & 65 & 62 \\
10 & 10 & $16.7 \% \mathrm{Ca}_{3} \mathrm{~N}_{2}$ & Heptane & 20 & 18 \\
11 & 5 & $16.7 \% \mathrm{Ca}_{3} \mathrm{~N}_{2}$ & Toluene & 100 & 96 \\
12 & 2.5 & $16.7 \% \mathrm{Ca}_{3} \mathrm{~N}_{2}$ & Toluene & 76 & 73 \\
13 & 1.25 & $16.7 \% \mathrm{Ca}_{3} \mathrm{~N}_{2}$ & Toluene & 69 & 66 \\
14 & 5 & $20 \% \mathrm{MgSO}_{4}$ & Toluene & 80 & 77 \\
15 & 5 & $20 \% \mathrm{Na}_{2} \mathrm{SO}_{4}$ & Toluene & 81 & 79 \\
$16^{e}$ & 5 & $16.7 \% \mathrm{Ca}_{3} \mathrm{~N}_{2}$ & Toluene & 100 & 97 \\
$17^{e}$ & 5 & $20 \%{\mathrm{Ca}(\mathrm{OH})_{2}}_{2}$ & Toluene & 99 & 95
\end{tabular}

${ }^{a}$ Conditions: $\mathrm{BnOH}(1 \mathrm{mmol}), \mathrm{CyNH}_{2}(1 \mathrm{mmol}), 2$ (X/100 mmol), additive, tetradecane ( $0.5 \mathrm{mmol}$, internal standard), 4 A MS (150 mg), solvent $(4 \mathrm{~mL})$, reflux, $48 \mathrm{~h} .{ }^{b}$ Determined by GC using the internal standard. ${ }^{c}$ GC yield based on the internal standard. ${ }^{d} 4 \%$ of $N$ cyclohexylbenzamide was also formed. ${ }^{e}$ Without 4 Å MS.

yields due to incomplete conversion of benzyl alcohol (entries 9 and 10). Under the reaction conditions, complex 2 is fully soluble at reflux in mesitylene, toluene and dioxane, but not in heptane. The catalyst loading could be adjusted to $5 \%$ without affecting the imine yield while $2.5 \%$ or $1.25 \%$ gave lower conversion of the alcohol (entries 11-13). The role of $\mathrm{Ca}_{3} \mathrm{~N}_{2}$ is probably to act as both a base and a desiccant (no byproducts were observed from a potential release of $\mathrm{NH}_{3}$ ). Replacing $\mathrm{Ca}_{2} \mathrm{~N}_{3}$ with $\mathrm{MgSO}_{4}$ or $\mathrm{Na}_{2} \mathrm{SO}_{4}$ led to a slower reaction (entries 14 and 15) while molecular sieves had no influence on the transformation (entry 16). $\mathrm{Ca}_{3} \mathrm{~N}_{2}$ reacts with water to form $\mathrm{Ca}(\mathrm{OH})_{2}$ and interestingly this salt gave almost the same result as $\mathrm{Ca}_{3} \mathrm{~N}_{2}$ (entry 17). Eventually, $5 \%$ of 2 and $16.7 \%$ of $\mathrm{Ca}_{3} \mathrm{~N}_{2}$ in refluxing toluene were chosen as the optimum conditions for conversion of equimolar amounts of alcohol and amine.

With the optimized catalyst system in place, the substrate scope of the imination reaction could now be investigated. Cyclohexylamine was first reacted with different alcohols and the imines were isolated by flash chromatography (Table 3). This produced $89 \%$ yield for the parent reaction with benzyl alcohol while the $p$-methyl analogue furnished $70 \%$ yield (entries 1 and 2). The $p$ - and $o$-methoxy substituted substrates afforded 83 and 90\% yield, respectively, while $p$-phenyl- and $p$-methylthiobenzyl alcohol both gave 60\% yield (entries 3-6). $p$-Nitrobenzyl alcohol is often a challenging substrate in dehydrogenative transformations due to an accompanying reduction of the nitro group, ${ }^{1}$ but this was not observed here and the imine was obtained in $70 \%$ yield (entry 7 ). A $p$-fluoro and a $p$ chloro substituent was also tolerated giving 73 and $85 \%$ yield (entries 8 and 9). The analogous bromo substrate reacted slightly slower although no competing dehalogenation was observed (entry 10). In addition, the two isomeric naphthalenemethanols gave the corresponding imines in 71 and $60 \%$ yield (entries 11 and 12). Full conversion of the alcohol was observed in all cases in Table 3 except for entries 5, 6, 10 and 12 where $5-10 \%$ of the alcohol remained and thus accounts for the isolated $\sim 60 \%$ yield.

The influence of the amine was then investigated by reacting benzyl alcohol with different primary amines (Table 4). Octylamine gave essentially the same result as cyclohexylamine (entry 1). The more hindered amines tert-octylamine and 1adamantylamine also gave full conversion of benzyl alcohol and furnished the imine in 69 and $88 \%$ yield, respectively (entries 2 and 3). Similar yields were obtained with the two optically pure amines (R)-1-phenylethylamine and (R)-1-(1-naphthyl)ethylamine although $10-15 \%$ of benzyl alcohol remained in both cases (entries 4 and 5). No sign of any racemization was observed in the two transformations indicating that dehydrogenation of the amine is not occurring under the reaction conditions. Benzhydrylamine gave the imine in $73 \%$ yield while tritylamine only furnished 19\% yield (entries 6 and 7 ). In the latter case, $48 \%$ of the intermediate benzaldehyde was also observed indicating a poor conversion into the imine with the very hindered amine. The inferior reactivity is most likely caused by $\mathrm{Ca}_{3} \mathrm{~N}_{2}$ since a control experiment with benzaldehyde, tritylamine and $\mathrm{Ca}_{3} \mathrm{~N}_{2}$ also showed incomplete imine formation. ${ }^{15}$ Furthermore, the imination could be performed with anilines where $74 \%, 63 \%$ and $62 \%$ yield were obtained with aniline, $p$-anisidine and $p$-trifluoromethylaniline, respectively (entries $8-10$ ). In entries 9 and 10 as well as in entries 5 and 6 about $10-30 \%$ of unreacted benzyl alcohol was also detected.

The reaction could be extended to the synthesis of pyrroles by reacting cis-but-2-ene-1,4-diol with primary amines. ${ }^{16}$ The transformation could be carried out with both aniline and cyclohexylamine to afford the desired product in moderate yield $^{\mathbf{1 7}}$ (Scheme 1).

The gas evolution was measured in a separate experiment under the optimized conditions in Table 2, entry 16, but without adding $\mathrm{Ca}_{3} \mathrm{~N}_{2}$ (resulting in a slightly lower $78 \%$ imine yield). One equivalent was collected and the gas was identified as dihydrogen, which confirms the acceptorless dehydrogenative pathway. Essentially no imine was formed when the reaction was conducted in the absence of complex 2 . The possibility for trace metal impurities is a serious concern in the development of reactions with new metal catalysts ${ }^{18}$ and studies have shown that some coupling reactions with manganese catalysts are most likely mediated by traces of other elements. ${ }^{19}$ For that reason, complex 2 was analyzed by inductively coupled plasma mass spectrometry (ICP-MS) for traces of other metals known to perform alcohol dehydrogenations. However, none of these elements could be detected beyond their detection limit and it is therefore highly unlikely that another metal is responsible for the observed results. 
Table 3 Imination of alcohols with cyclohexylamine ${ }^{a}$

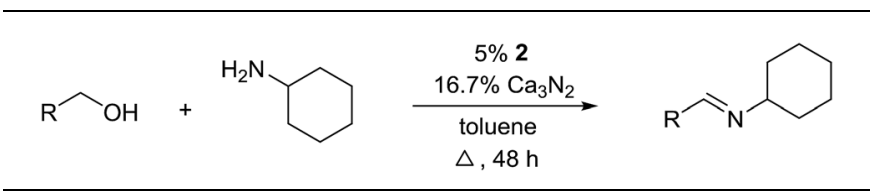

\begin{tabular}{|c|c|c|c|}
\hline Entry & Alcohol & Imine & Yield $^{b}(\%)$ \\
\hline
\end{tabular}

1<smiles>OCc1ccccc1</smiles>

2<smiles>Cc1ccc(CO)cc1</smiles>

(1)<smiles>COc1ccc(CO)cc1</smiles><smiles>COc1ccccc1CO</smiles>

4<smiles>OCc1ccc(-c2ccccc2)cc1</smiles><smiles>CSc1ccc(CO)cc1</smiles><smiles>O=[N+]([O-])c1ccc(CO)cc1</smiles>

8<smiles>OCc1ccc(F)cc1</smiles><smiles>OCc1ccc(Cl)cc1</smiles><smiles>Clc1ccc(/C=N/C2CCCCC2)cc1</smiles>

Table 3 (Contd.)

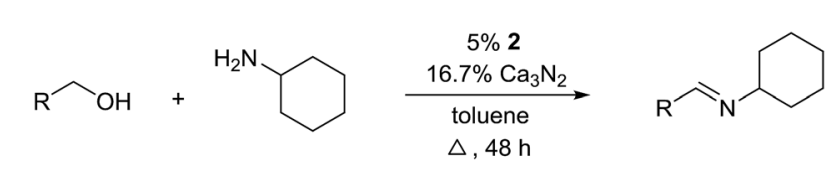

\begin{tabular}{|c|c|c|c|}
\hline Entry & Alcohol & Imine & Yield $^{b}(\%)$ \\
\hline
\end{tabular}

12<smiles>OCc1cccc2ccccc12</smiles><smiles>C(=N/C1CCCCC1)\c1cccc2ccccc12</smiles>

60

\begin{abstract}
${ }^{a}$ Conditions: alcohol ( $\left.1 \mathrm{mmol}\right), \mathrm{CyNH}_{2}(1 \mathrm{mmol}), 2$ (0.05 mmol), $\mathrm{Ca}_{3} \mathrm{~N}_{2}$ $(0.167 \mathrm{mmol})$, toluene $(4 \mathrm{~mL})$, reflux, $48 \mathrm{~h} .{ }^{b}$ Isolated yield. ${ }^{c}$ Reaction time $72 \mathrm{~h}$.
\end{abstract}

As mentioned above, complex 2 dissolves completely in toluene upon heating the mixture to reflux. However, after the imination has gone to completion and the reaction is cooled to room temperature, complex 2 precipitates out again and 95\% can be recovered after addition of a small amount of hexane. Furthermore, the retrieved complex can be subjected to a new catalytic reaction which gave $82 \%$ yield of the imine with a $4.5 \%$ catalyst loading.

When the optimized reaction in Table 2, entry 16 was performed with $\mathrm{PhCD}_{2} \mathrm{OH}$ instead of $\mathrm{PhCH}_{2} \mathrm{OH}$, the product was exclusively $\mathrm{PhCD}=\mathrm{NCy}$ with no hydrogen incorporation into the benzylic position. This may imply that the dehydrogenation takes place by a monohydride pathway and no metal-dihydride species is formed.

To investigate whether the hydride abstraction takes place in the rate-limiting step, the primary kinetic isotope effect (KIE) was measured. The initial rate was determined with both $\mathrm{PhCD}_{2} \mathrm{OH}$ and $\mathrm{PhCH}_{2} \mathrm{OH}$ in the reaction with cyclohexylamine which gave a KIE of 2.00. This somewhat modest value shows that breakage of the $\mathrm{C}-\mathrm{H}$ bond is one of several slow steps in the transformation.

To gain more experimental information about the reaction pathway, the studies were also supplemented by a Hammett study where the change in charge at the benzylic position between the starting material and the transition state can be determined. We have previously used Hammett studies with para-substituted benzyl alcohols to analyze the rate-limiting step in dehydrogenations catalyzed by ruthenium and iridium complexes. ${ }^{20}$ Thus, five para-substituted benzyl alcohols ( $\mathrm{X}=$ $\mathrm{OCH}_{3}, \mathrm{CH}_{3}, \mathrm{~F}, \mathrm{Cl}$ and $\mathrm{NO}_{2}$ ) were allowed to compete with the parent benzyl alcohol in the imination with cyclohexylamine. The reactions were monitored by GC, which allowed for determining the consumption of each alcohol. Assuming a first order reaction in the alcohol, their relative reactivities $\left(k_{\mathrm{X}} / k_{\mathrm{H}}\right)$ can be determined as the slope of the line when $\ln \left(c_{0} / c\right)$ for one parasubstituted benzyl alcohol is plotted against the same values for benzyl alcohol. These plots gave straight lines for all five parasubstituted benzyl alcohols and made it possible to use the 
Table 4 Imination of amines with benzyl alcohol ${ }^{a}$

$\mathrm{OH}_{+} \frac{\mathrm{H}_{2} \mathrm{~N}-\mathrm{R}}{\substack{\text { toluene } \\ \triangle, 48 \mathrm{~h}}}$

\begin{tabular}{|c|c|c|c|}
\hline Entry & Amine & Imine & Yield $^{b}(\%)$ \\
\hline
\end{tabular}

1 $\mathrm{H}_{2} \mathrm{~N} \Upsilon \mathrm{T}_{6}$<smiles>CCCN=Cc1ccccc1</smiles>

2<smiles>CC(C)(C)CC(C)(C)N</smiles><smiles>CC(C)(C)CC(C)(C)/N=C/c1ccccc1</smiles>

3<smiles>NC12CC3CC(CC(C3)C1)C2</smiles><smiles>C(=NC12CC3CC(CC(C3)C1)C2)c1ccccc1</smiles>

4<smiles>C[C@H](N)c1ccccc1</smiles><smiles>C[C@H](N=Cc1ccccc1)c1ccccc1</smiles>

5<smiles>C[C@H](N)c1cccc2ccccc12</smiles><smiles>C[C@H](/N=C/c1ccccc1)c1cccc2ccccc12</smiles>

6<smiles>NC(c1ccccc1)c1ccccc1</smiles><smiles>C(=N/C(c1ccccc1)c1ccccc1)\c1ccccc1</smiles><smiles>NC(c1ccccc1)(c1ccccc1)c1ccccc1</smiles><smiles>C(=NC(c1ccccc1)(c1ccccc1)c1ccccc1)c1ccccc1</smiles>

8<smiles>Nc1ccccc1</smiles><smiles>C(=N/c1ccccc1)\c1ccccc1</smiles><smiles>COc1ccc(N)cc1</smiles><smiles>COc1ccc(/N=C/c2ccccc2)cc1</smiles>

10<smiles>Nc1ccc(C(F)(F)F)cc1</smiles><smiles>FC(F)(F)c1ccc(/N=C/c2ccccc2)cc1</smiles>

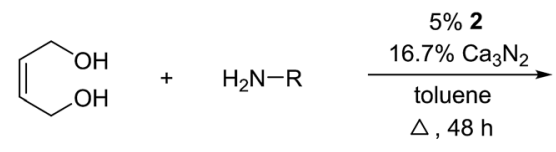

$\mathrm{R}=\mathrm{Ph}: 47 \%$ yield
$\mathrm{R}=\mathrm{Cy}: 62 \%$ yield

Scheme 1 Pyrrole synthesis from but-2-ene-1,4-diol and amines.

with a hydride transfer from the alcohol. Attempts to use different sets of $\sigma$ values $^{22}$ gave a poor correlation and radical intermediates are therefore not involved in the catalytic cycle. This was also confirmed by conducting the imination in the presence of one equiv. of the radical trapping agents cyclohexa1,4-diene and 2,4-diphenyl-4-methylpent-1-ene which in both cases had no influence on the imine yield.

To further understand the mechanism, we used density functional theory (DFT) calculations to estimate the Gibbs free energies of possible intermediates and transition states. The starting point was the $\mathrm{Mn}($ salen)OBn complex $\mathbf{9}$, where $\mathrm{Cl}$ has been replaced by a benzylic alkoxide (Fig. 4). This transformation involves the elimination of $\mathrm{HCl}$, which is possible under the basic conditions. In fact, an experiment in the absence of a base (complex 2 and benzyl alcohol) gave no conversion at all while the absence of the amine (complex 2, benzyl alcohol and $\mathrm{Ca}_{3} \mathrm{~N}_{2}$ ) resulted in $20 \%$ of benzyl benzoate.

The initial idea was that complex 9 undergoes $\beta$-hydride elimination. However, the activation energy for this process was found to be prohibitively high (at $37.9 \mathrm{kcal} \mathrm{mol}^{-1}$ relative to 9) which is partly due to the lack of an available coordination site. Instead, we found an alternative reaction where the hydride is transferred from the benzylic carbon to the imine carbon of the salen ligand. The activation energy was merely $17.6 \mathrm{kcal} \mathrm{mol}^{-1}$ and the product complex 11 is at $6.6 \mathrm{kcal} \mathrm{mol}^{-1}$. A similar pathway has been identified in the activation of (PNNP)Fe(II) eneamido complexes with isopropanol. ${ }^{23}$ The product benzaldehyde is then replaced by benzyl alcohol, from which a proton is transferred to the amide nitrogen of the reduced salen ligand. The resulting complex where one imine of the salen is

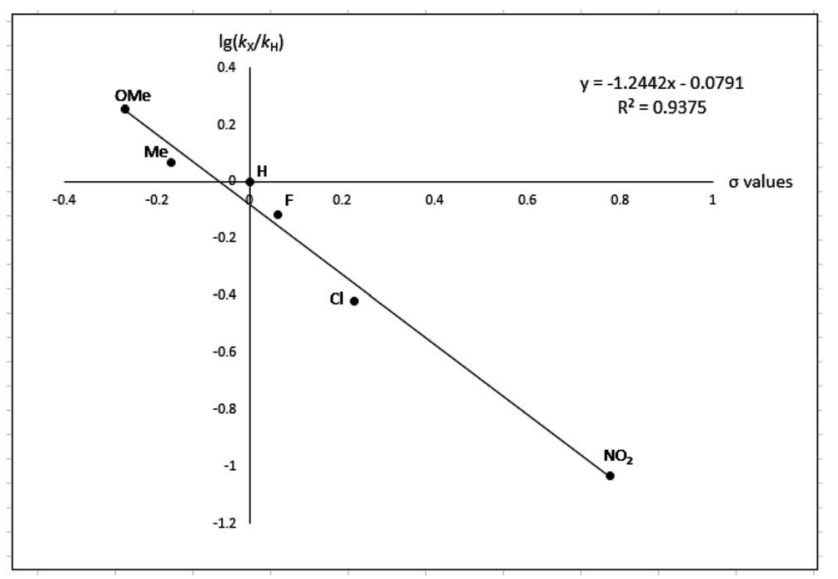

Fig. 3 Hammett plot for the imination with para-substituted benzyl alcohols. 

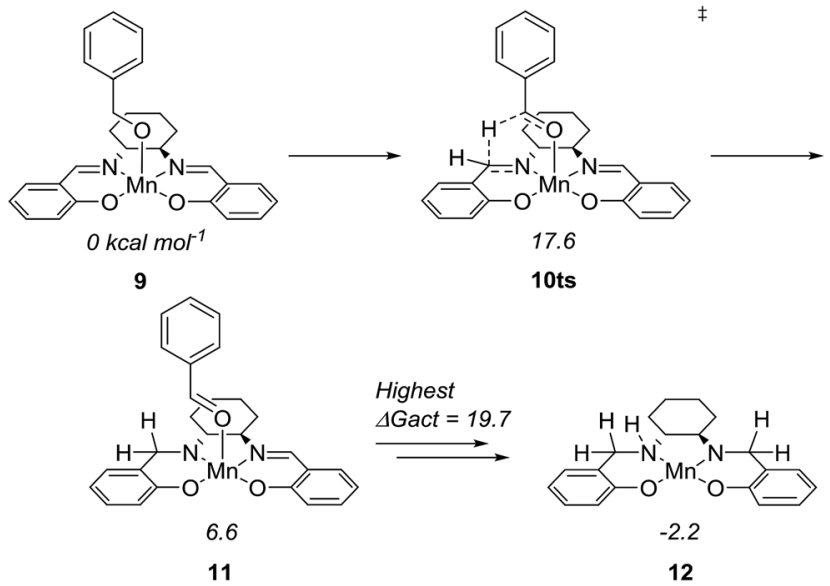

Fig. 4 Activation of $\mathrm{Mn}(\mathrm{III})($ salen)OBn to form the active amido complex.

hydrogenated is at $-5.2 \mathrm{kcal} \mathrm{mol}^{-1}$ relative to 9 . The lowest activation energy found from the hydrogenated intermediate was for another hydride transfer to the second imine of the salen, with a transition state at $14.5 \mathrm{kcal} \mathrm{mol}^{-1}$ (maximum $\Delta G_{\text {act }}$ $=19.7 \mathrm{kcal} \mathrm{mol}{ }^{-1}$, see ESI $\dagger$ for more details).

After complete dissociation of benzaldehyde a key species $\mathbf{1 2}$ is formed, where one imine is hydrogenated to the amine and the other is reduced to an amide ligand. This species resembles intermediates from alcohol dehydrogenations with (PNP)Ru(II), (PNP)Mn(I), (PNNP)Fe(II) and (PNP)Ir(III) catalysts ${ }^{24}$ which have an amide ligand that can act as a Brønsted base and a metal that can serve as a hydride acceptor. They have all been proposed to react via an outer-sphere hydrogen transfer mechanism. ${ }^{24}$ The main difference is the metal and the oxidation state, which in the current case is manganese(III). The same outer-sphere hydrogen transfer was identified here and the activation energy is $26.7 \mathrm{kcal} \mathrm{mol}^{-1}$ relative to $\mathbf{1 2}$ and $27.2 \mathrm{kcal} \mathrm{mol}^{-1}$ relative to 15 , which corresponds to a TOF of $83 \mathrm{~h}^{-1}$ at the reaction conditions (Fig. 5). The calculated KIE of this reaction is 2.9, which is in reasonable agreement with the experimental value of 2.0. Finally, we calculated the relative rates of the parasubstituted benzyl alcohols used in the experimental study. The relative rates were calculated from the prereactive complex $\mathbf{1 5}$ and a good agreement was found with the experimental results giving a very similar $\rho$ value (Fig. 6). After the formation of the manganese(III) hydride intermediate 17 , benzaldehyde is assumed to react irreversibly with the amine. From complex 17 the formation of hydrogen gas requires an activation energy of $22.6 \mathrm{kcal} \mathrm{mol}^{-1}$, in a step that regenerates the active catalyst.

The proposed mechanism indicates that the Schiff base functionality of the salen ligand is crucial for the reactivity. This was also confirmed by isolating the salen complex after the imination reaction with $\mathrm{PhCD}_{2} \mathrm{OH}$ and cyclohexylamine. The isolated complex showed the incorporation of one deuterium atom on each of the Schiff base carbons as would be expected from the proposed mechanism. The involvement of the Schiff base was also observed in the optimization where both the salen complex $\mathbf{2}$ and the salan complex $\mathbf{8}$ catalyzed the

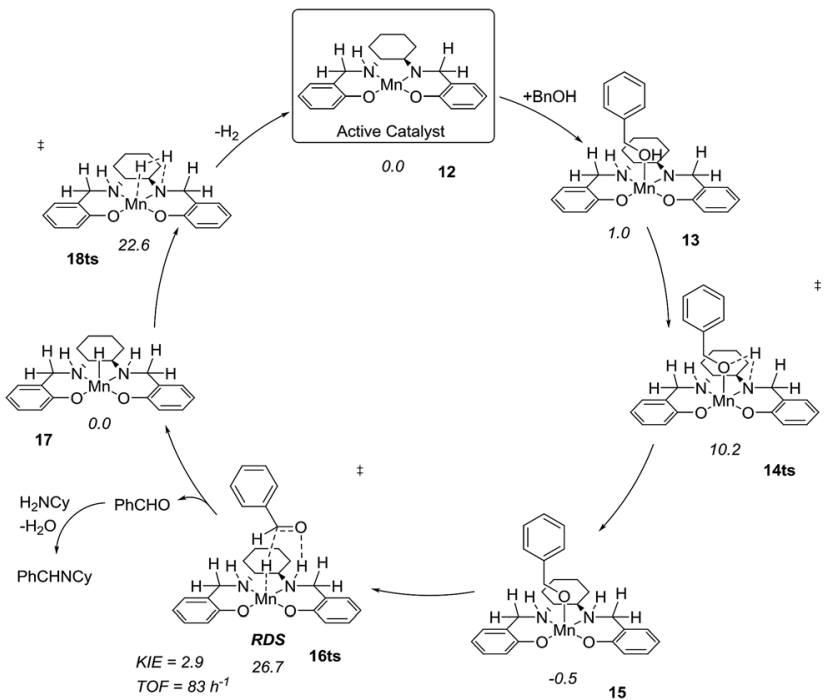

Fig. 5 Proposed catalytic cycle and relative Gibbs free energies.

dehydrogenation although the latter in a low yield (Table 1). When the imination with $5 \%$ of the salan complex 8 was repeated with $\mathrm{KO} t \mathrm{Bu}$ as the base, a $56 \%$ yield was obtained of $\mathrm{N}$ benzylidene cyclohexylamine. This result can be explained by elimination of $\mathrm{HCl}$ from $\mathbf{8}$ to afford the catalytically active species 12. ${ }^{25}$ Similar eliminations of hydrogen halides under basic conditions have been described with (PNP)Mn(I), (PNP) $\mathrm{Ru}$ (II) and (PNNP)Fe(II) complexes to form the corresponding amido compounds. ${ }^{4 b, 26}$ Notably, a post analysis by LCMS of the imination with salan complex 8 showed the formation of salen complex $\mathbf{2}$ as the main manganese species together with minor amounts of some unidentified complexes. None of the starting complex 8 could be detected after the imination. These observations show that a salan complex can be converted into the corresponding salen complex under the reaction conditions and explains why salen complex $\mathbf{2}$ is almost fully recovered after the reaction. So far, however, we have not been able to identify

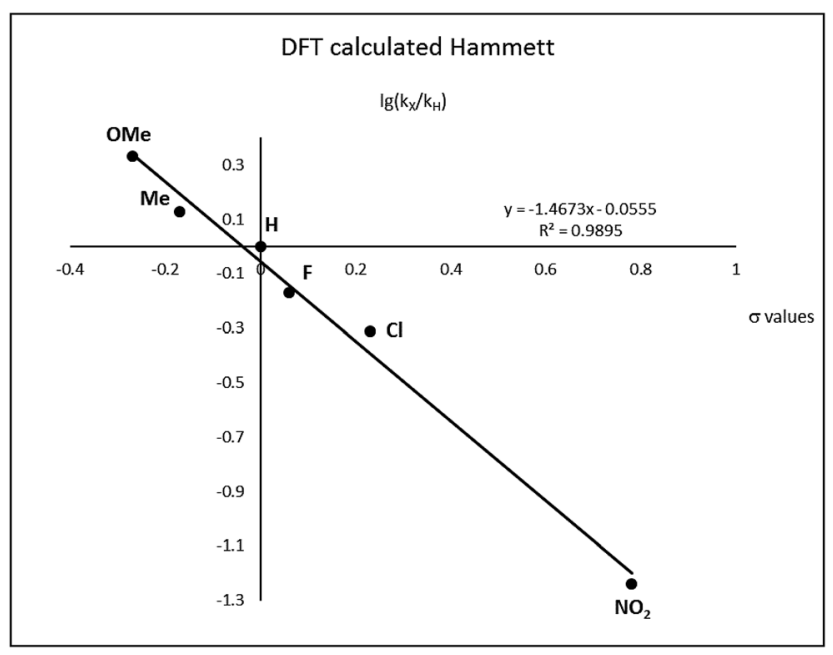

Fig. 6 Hammett plot calculated by DFT. 
a pathway by which hydrogen is eliminated from a salan complex to afford the salen compound.

\section{Conclusions}

In summary, we have described a new catalyst for the acceptorless dehydrogenation of alcohols. The manganese(III) salen complex 2 mediates the formation of imines from alcohols and amines with the liberation of hydrogen gas. The reaction can be performed with different alcohols and amines and can be extended to the synthesis of pyrroles. Complex 2 can be recovered from the reaction and used again without significantly affecting the catalytic activity. The mechanism is believed to involve a bifunctional pathway where both the metal and the ligand participates in the dehydrogenation reaction. We envision the discoveries will spur much interest in the development of new transformations with hydrogen gas and manganese(III) catalysts.

\section{Conflicts of interest}

There are no conflicts to declare.

\section{Acknowledgements}

The project was supported by the Technical University of Denmark through PhD fellowships to SVS and CS. We thank Mathias Børsting for his assistance in performing the Hammett study and determining the KIE.

\section{Notes and references}

1 (a) A. Corma, J. Navas and M. J. Sabater, Chem. Rev., 2018, 118, 1410-1459; (b) C. Gunanathan and D. Milstein, Science, 2013, 341, 1229712; (c) S. Bähn, S. Imm, L. Neubert, M. Zhang, H. Neumann and M. Beller, ChemCatChem, 2011, 3, 1853-1864; (d) Y. Obora and Y. Ishii, Synlett, 2011, 30-51; (e) R. Yamaguchi, K. Fujita and M. Zhu, Heterocycles, 2010, 81, 1093-1140; (f) A. J. A. Watson and J. M. J. Williams, Science, 2010, 329, 635-636; $(g)$ G. E. Dobereiner and R. H. Crabtree, Chem. Rev., 2010, 110, 681-703.

2 (a) G. A. Filonenko, R. van Putten, E. J. M. Hensen and E. A. Pidko, Chem. Soc. Rev., 2018, 47, 1459-1483; (b) F. Kallmeier and R. Kempe, Angew. Chem., Int. Ed., 2018, 57, 46-60; (c) B. Maji and M. K. Barman, Synthesis, 2017, 49, 3377-3393; (d) M. Garbe, K. Junge and M. Beller, Eur. J. Org. Chem., 2017, 4344-4362; (e) E. Balaraman, A. Nandakumar, G. Jaiswal and M. K. Sahoo, Catal. Sci. Technol., 2017, 7, 3177-3195; $(f)$ A. Quintard and J. Rodrigues, ChemSusChem, 2016, 9, 28-30.

3 A. Mukherjee, A. Nerush, G. Leitus, L. J. W. Shimon, Y. Ben David, N. A. E. Jalapa and D. Milstein, J. Am. Chem. Soc., 2016, 138, 4298-4301.

4 (a) N. A. Espinosa-Jalapa, A. Kumar, G. Leitus, Y. DiskinPosner and D. Milstein, J. Am. Chem. Soc., 2017, 139, 11722-11725; (b) S. Chakraborty, U. Gellrich, Y. Diskin-
Posner, G. Leitus, L. Avram and D. Milstein, Angew. Chem., Int. Ed., 2017, 56, 4229-4233; (c) J. Neumann, S. Elangovan, A. Spannenberg, K. Junge and M. Beller, Chem.-Eur. J., 2017, 23, 5410-5413; (d) N. Deibl and R. Kempe, Angew. Chem., Int. Ed., 2017, 56, 1663-1666; (e) M. Mastalir, M. Glatz, N. Gorgas, B. Stöger, E. Pittenauer, G. Allmaier, L. F. Veiros and K. Kirchner, Chem.-Eur. J., 2016, 22, 12316-12320; $(f)$ S. Elangovan, J. Neumann, J.-B. Sortais, K. Junge, C. Darcel and M. Beller, Nat. Commun., 2016, 7, 12641.

5 (a) V. Papa, J. R. Cabrero-Antonino, E. Albericio, A. Spannenberg, K. Junge, H. Junge and M. Beller, Chem. Sci., 2017, 8, 3576-3585; (b) N. A. Espinosa-Jalapa, A. Nerush, L. J. W. Shimon, G. Leitus, L. Avram, Y. BenDavid and D. Milstein, Chem.-Eur. J., 2017, 23, 5934-5938; (c) S. Elangovan, M. Garbe, H. Jiao, A. Spannenberg, K. Junge and M. Beller, Angew. Chem., Int. Ed., 2016, 55, 15364-15368; (d) F. Kallmeier, T. Irrgang, T. Dietel and R. Kempe, Angew. Chem., Int. Ed., 2016, 55, 11806-11809; (e) S. Elangovan, C. Topf, S. Fischer, H. Jiao, A. Spannenberg, W. Baumann, R. Ludwig, K. Junge and M. Beller, J. Am. Chem. Soc., 2016, 138, 8809-8814.

6 For additional examples, see: $(a)$ D. Wei, A. Bruneau-Voisine, T. Chauvin, V. Dorcet, T. Roisnel, D. A. Valyaev, N. Lugan and J.-B. Sortais, Adv. Synth. Catal., 2018, 360, 676-681; (b) A. Kumar, N. A. Espinosa-Jalapa, G. Leitus, Y. DiskinPosner, L. Avram and D. Milstein, Angew. Chem., Int. Ed., 2017, 56, 14992-14996; (c) S. Chakraborty, U. Kumar Das, Y. Ben-David and D. Milstein, J. Am. Chem. Soc., 2017, 139, 11710-11713; (d) F. Kallmeier, B. Dudziec, T. Irrgang and R. Kempe, Angew. Chem., Int. Ed., 2017, 56, 7261-7265; (e) M. Mastalir, M. Glatz, E. Pittenauer, G. Allmaier and K. Kirchner, J. Am. Chem. Soc., 2016, 138, 15543-15546; (f) M. Peña-López, P. Piehl, S. Elangovan, H. Neumann and M. Beller, Angew. Chem., Int. Ed., 2016, 55, 14967-14971.

7 (a) P. L. Pauson and G. K. Friestad, e-EROS, 2008, DOI: 10.1002/047084289x.rd001.pub2; (b) Y. Xie, J. H. Jang, R. B. King and H. F. Schaefer III, Inorg. Chem., 2003, 42, 5219-5230.

8 (a) J. F. Larrow, E. N. Jacobsen, Y. Gao, Y. Hong, X. Nie and C. M. Zepp, J. Org. Chem., 1994, 59, 1939-1942; (b) E. N. Jacobsen, W. Zhang, A. R. Muci, J. R. Ecker and L. Deng, J. Am. Chem. Soc., 1991, 113, 7063-7064.

9 (a) W. Liu and J. T. Groves, Acc. Chem. Res., 2015, 48, 17271735; (b) R. I. Khusnutdinov, A. R. Bayguzina and U. M. Dzhemilev, Russ. J. Org. Chem., 2012, 48, 309-348; (c) E. M. McGarrigle and D. G. Gilheany, Chem. Rev., 2005, 105, 1563-1602; (d) T. Katsuki, Synlett, 2003, 281-297.

10 For recent reviews on the synthesis of imines from alcohols and amines, see: (a) B. Chen, L. Wang and S. Gao, ACS Catal., 2015, 5, 5851-5876; (b) R. D. Patil and S. Adimurthy, Asian J. Org. Chem., 2013, 2, 726-744.

11 (a) P. A. Dub and J. C. Gordon, ACS Catal., 2017, 7, 66356655; (b) J. R. Khusnutdinova and D. Milstein, Angew. Chem., Int. Ed., 2015, 54, 12236-12273; (c) R. H. Morris, Acc. Chem. Res., 2015, 48, 1494-1502. 
12 Complex 1 is commercially available, but in our hands its catalytic performance in the dehydrogenation depended on the supplier. Therefore, all manganese(III) complexes used in this work were synthesized by standard literature protocols and no commercial samples were used. The presynthesized complexes gave reproducible results and could be stored at room temperature under an inert atmosphere for a longer period without affecting the product yield.

$13 \mathrm{KOH}, \mathrm{NaOH}, \mathrm{LiOH}, \mathrm{KO} t \mathrm{Bu}, \mathrm{K}_{3} \mathrm{PO}_{4}, \mathrm{Cs}_{2} \mathrm{CO}_{3}, \mathrm{AgBF}_{4}, \mathrm{Et}_{3} \mathrm{~N}$, $\mathrm{MgBr}_{2}, \mathrm{MgO}, \mathrm{LiCl}, \mathrm{LiBr}$, and $\mathrm{LiF}$.

14 I. S. Makarov and R. Madsen, J. Org. Chem., 2013, 78, 65936598.

15 Tritylamine reacts quantitatively with benzaldehyde in benzene in the absence of additives, see: M. Soroka and J. Zygmunt, Synthesis, 1988, 370-372.

16 For iron- and palladium-catalyzed synthesis of pyrroles from but-2-ene-1,4-diol and amines, see: (a) B. Emayavaramban, M. Sen and B. Sundararaju, Org. Lett., 2017, 19, 6-9; (b) T. Yan and K. Barta, ChemSusChem, 2016, 9, 2321-2325; (c) S. I. Murahashi, T. Shimamura and I. Moritani, J. Chem. Soc., Chem. Commun., 1974, 931-932.

17 Similar yields are reported in ref. 16.

18 I. Thomé, A. Nijs and C. Bolm, Chem. Soc. Rev., 2012, 41, 979987.

19 C. Santilli, S. S. Beigbaghlou, A. Ahlburg, G. Antonacci, P. Fristrup, P.-O. Norrby and R. Madsen, Eur. J. Org. Chem., 2017, 5269-5274.

20 (a) I. S. Makarov, P. Fristrup and R. Madsen, Chem.-Eur. J., 2012, 18, 15683-15692; (b) P. Fristrup, M. Tursky and R. Madsen, Org. Biomol. Chem., 2012, 10, 2569-2577.
21 C. Hansch, A. Leo and R. W. Taft, Chem. Rev., 1991, 91, 165195.

22 (a) X. Creary, Acc. Chem. Res., 2006, 39, 761-771; (b) X.-K. Jiang and G.-Z. Ji, J. Org. Chem., 1992, 57, 6051-6056; (c) J. M. Dust and D. R. Arnold, J. Am. Chem. Soc., 1983, 105, 1221-1227.

23 D. E. Prokopchuk and R. H. Morris, Organometallics, 2012, 31, 7375-7385.

24 (a) D. H. Nguyen, X. Trivelli, F. Capet, Y. Swesi, A. FavreRéguillon, L. Vanoye, F. Dumeignil and R. M. Gauvin, ACS Catal., 2018, 8, 4719-4734; (b) D. H. Nguyen, X. Trivelli, F. Capet, J.-F. Paul, F. Dumeignil and R. M. Gauvin, ACS Catal., 2017, 7, 2022-2032; (c) A. A. Mikhailine, M. I. Maishan, A. J. Lough and R. H. Morris, J. Am. Chem. Soc., 2012, 134, 12266-12280; (d) S. Bi, Q. Xie, X. Zhao, Y. Zhao and X. Kong, J. Organomet. Chem., 2008, 693, 633638.

25 This elimination does not appear to be a very facile reaction, which may explain the lower yield of the imine with complex $\mathbf{8}$ as the catalyst. Treatment of complex $\mathbf{8}$ with one equiv. of $\mathrm{KO} t \mathrm{Bu}$ in refluxing toluene in the absence of the substrates showed no conversion into other manganese compounds after $1 \mathrm{~h}$ according to LCMS. Upon prolonged treatment, other manganese species were formed with complex 2 as the main compound after $48 \mathrm{~h}$.

26 (a) E. Alberico, A. J. J. Lennox, L. K. Vogt, H. Jiao, W. Baumann, H.-J. Drexler, M. Nielsen, A. Spannenberg, M. P. Checinski, H. Junge and M. Beller, J. Am. Chem. Soc., 2016, 138, 14890-14904; (b) W. Zuo, D. E. Prokopchuk, A. J. Lough and R. H. Morris, ACS Catal., 2016, 6, 301-314. 